\title{
ECONOMIA SOLIDÁRIA E INCLUSÃO SOCIAL: PRÁTICA INOVADORA PARA A GERAÇÃO DE TRABALHO E RENDA ${ }^{1}$
}

Edilene Mayumi Murashita Takenaka, Renato Bertoni, Stephanie Funari Amaral Gusmão

Universidade do Oeste Paulista - UNOESTE, curso de Mestrado em Meio Ambiente e Desenvolvimento Regional MMADRE, Presidente Prudente, SP. e-mail: stephaniefagusmao@gmail.com

\section{RESUMO}

A Economia Solidária pode ser definida como o conjunto de atividades econômicas de produção, distribuição, consumo, poupança e crédito, organizadas sob a forma de autogestão e seu surgimento pode ser explicado pela ocorrência do desemprego estrutural, em virtude da substituição de pessoas por máquinas. Visa reduzir as desigualdades sociais em parceria com o Estado, além de, ofertar empregos para quem não se enquadra mais no mercado de trabalho capitalista, visando de certa forma a inclusão social. A Economia Solidária visa a igualdade social e o trabalho coletivo, além da autonomia. $\mathrm{O}$ objetivo do presente artigo é apontar potencialidades e fragilidades que podem ser observadas dentro da Economia Solidária enquanto estratégia de ação do Estado que busca a inserção social da população brasileira. Para tanto, foi feita uma pesquisa bibliográfica levando em conta a proposta da Economia Solidária enquanto estratégia de ação para a obtenção da igualdade social a partir de uma prática inovadora e alternativa de geração de trabalho e renda a favor da inclusão social.

Palavras-chave: Economia Solidária, Inclusão social, Geração de renda, Desemprego estrutural, Autogestão.

\section{SOLIDARITY ECONOMY AND SOCIAL INCLUSION: AN INNOVATIVE PRACTICE TO WORK AND INCOME GENERATION.}

\begin{abstract}
The Solidarity Economy can be defined as the set of economic activities of production, distribution, consumption, savings and credit, organized in the form of self-management and its appearance can be explained by the occurrence of the structural unemployment, due to the displacement of people by machines. It aims to reduce social inequalities in partnership with the State, besides offering jobs for those who do not fit anymore in the capitalist labor market, aiming somehow social inclusion. The Solidarity Economy aims the social equality and collective work, besides autonomy. The purpose of this article is pointing out strengths and weaknesses that can be observed within the Solidarity Economy as an action strategy of the State that seeks social inclusion of the Brazilian population. Therefore, a literature search was made taking into account the proposal of the Solidarity Economy as action strategy for achieving social equality from an innovative and practical alternative source of work and income for social inclusion.

Keywords: Solidarity Economy, Social inclusion, Income generation, Structural unemployment, Self-management.
\end{abstract}

\footnotetext{
${ }^{1} \mathrm{O}$ presente artigo é resultado de estudos realizados na disciplina Meio Ambiente e Economia Solidária do curso de Mestrado em Meio Ambiente e Desenvolvimento Regional/Unoeste.
} 


\section{INTRODUÇÃO}

As políticas públicas no Brasil trazem, na maior parte dos casos, a marca do assistencialismo na medida em que caracterizam-se como mecanismos e/ou instrumentos que o Estado faz uso para buscar a melhoria da qualidade de vida da população. Além disso, visa desenvolver ações de inclusão social, em um público definido pelo nível de pobreza entre pessoas desempregadas que, na maioria das vezes, apresentam-se como mão-de-obra desqualificada com dificuldades de inserção no mercado de trabalho formal.

Segundo Barros (2015), dificilmente pensamos que as pessoas são excluídas do meio social em razão das características físicas que possuem, pois já nascemos com essas características e não podemos mudá-las e nem ser culpados por possuí-las. Sendo assim, a inclusão social está ligada as pessoas que não têm as mesmas oportunidades dentro da sociedade. Muitos são excluídos por causa da baixa escolaridade, da discriminação do local de moradia, da idade, por não possuírem condições financeiras, questões raciais e, em alguns casos, por serem portadores de deficiências físicas ou mentais.

De acordo com Barros (2015), as diferenças enriquecem a vida de todos, só que dentro da nossa cultura temos uma experiência mínima em relação à inclusão social, pois existem pessoas que ainda criticam a igualdade de direitos e não querem colaborar com aqueles que não estão dentro dos padrões de normalidade, estabelecido por um grupo que é maioria. Mas, é sempre bom lembrar que as diferenças se fazem iguais quando essas pessoas são colocadas em um grupo que as aceite, acrescentando valores morais e de respeito ao próximo, tendo os mesmos direitos e recebendo as mesmas oportunidades diante da vida.

De acordo com Costa (2010, p.144)

A política pública compreende um elenco de ações e procedimentos que visam à resolução de problemas sociais em torno da alocação de bens e recursos públicos, destacando-se que os personagens envolvidos neste conflito são denominastes de atores públicos.

Sendo assim, as políticas públicas são ações governamentais, que visam reduzir as desigualdades das pessoas que não vivem em plenas condições de cidadania. A maioria dessa população não tem oportunidade de emprego, por não se enquadrarem mais no mercado de trabalho.

Com o avanço do uso da tecnologia nas atividades produtivas, como a nova forma de organização do trabalho e da produção, a vaga do trabalhador foi ocupada por máquinas ou por 
processos produtivos mais modernos para a realização do serviço e com isso surge a era do desemprego estrutural.

De acordo com Oliveira (2004)

Contudo, o desemprego estrutural, aquele em que a vaga do trabalhador foi substituída por máquinas ou processos produtivos mais modernos, não se resolve apenas pelo crescimento econômico. Aquele trabalho executado por dezenas de trabalhadores agora só necessita de um operador, ou melhor, dezenas de empregos transformam-se em apenas um.

Sendo assim, a utilização da tecnologia no processo produtivo pode ser considerada como um dos fatores que levam à diminuição do emprego, mas não só em relação a aquisições de máquinas, pois também há pessoas que não querem ou não conseguem se adequar as mudanças, sendo assim, excluídas do mercado de trabalho. Além disso, o desemprego estrutural não é novidade para a humanidade, pois a cada dia que passa surgem mais inovações, para que as empresas não fiquem estacionadas.

Para promover a geração de trabalho, elevar a renda e diminuir os efeitos do desemprego estrutural, foram criadas algumas propostas no Brasil e uma delas é a adoção da Economia Solidária.

De acordo com Pitaguari, Cordeiro e Lanza (2012, p.75)

Nos anos 2000, no Brasil, com o presidente da república, Luiz Inácio Lula da Silva, a Economia Solidária recebe o estatuto de política pública federal, inserindo-se no Ministério do Trabalho e Emprego pela Secretária Nacional de Economia Solidária (SENAES), por meio da Lei no 10.683 de 28 de maio de 2003 e do Decreto no 4764 de 24 de junho de 2003. Concomitante a esse processo, cria-se o Fórum Brasileiro de Economia Solidária (FBES), que tem a função de articular as experiências da Economia Solidária no Brasil e representa-las juntamente ao governo.

Portanto, a economia solidária só veio à tona com o crescimento da exclusão, das desigualdades sociais e da insuficiência dos modelos de Estado, só que ela já existia no Brasil no XIX, e permaneceu adormecida boa parte do século XX, voltando forte na última década.

O que o presente artigo busca é apontar potencialidades e fragilidades que podem ser observadas dentro da Economia Solidária enquanto estratégia de ação do Estado que busca a inserção social da população brasileira. 


\section{METODOLOGIA}

A abordagem metodológica depende essencialmente da proposta que o artigo pretende desempenhar, sendo assim neste trabalho foi realizada uma pesquisa bibliográfica, feita através de livros e artigos específicos de autores renomados sobre o tema, levando em conta a proposta da Economia Solidária enquanto estratégia de ação para a obtenção da igualdade social a partir de uma prática inovadora e alternativa de geração de trabalho e renda a favor da inclusão social.

\section{DESENVOLVIMENTO E DISCUSSÃO}

\section{Economia solidária: um breve arcabouço teórico}

Nos últimos tempos, a economia solidária surge como uma alternativa para geração de trabalho e renda para as pessoas que se encontram fora do mercado profissional, ou seja, desempregados que buscam se colocar novamente no mercado. A crise do desemprego deu início a iniciativas de economia solidária já que atualmente vêm se ampliando de forma considerável o número de pessoas fora do meio formal de trabalho.

De acordo com Singer (2003, p.13)

A economia solidária surge como modo de produção e distribuição alternativo ao capitalismo, criado e recriado periodicamente pelos que se encontram (ou temem ficar) marginalizados do mercado de trabalho. A economia solidária casa o princípio da unidade entre posse e uso dos meios de produção e distribuição (da produção simples de mercadorias) com o princípio da socialização destes meios (do capitalismo). Sob o capitalismo, os meios de produção são socializados na medida em que o progresso técnico cria sistemas que se podem ser alterados por grandes números de pessoas, agindo coordenadamente, ou seja, cooperando entre si. Isso se dá não somente nas fábricas, mas também nas redes de transportes, comunicação, de suprimento de energia, de água, de vendas no varejo etc.

Com isso, o modo solidário é uma criação em processo contínuo de trabalhadores contra o capitalismo. Além disso, dentro da economia solidária a cooperativa de produção tem meios de produção em pequena escala e a autogestão que possui uma forma de cooperação democrática entre os cooperados. Mas, isso não acontece no meio capitalista, pois normalmente trabalham de acordo com o sistema que, visa à acumulação do capital e a produção de grande escala.

Também, consideramos que a economia solidária vem ganhando amplitude através de movimentos sociais e como objeto de estudo de políticas públicas, pois se observam cada vez mais que este assunto ganha novos rumos e soluções através de pesquisas acadêmicas que tem como proposta apresentar de forma clara a intenção da economia solidária. 
A Economia Solidária é definida como o conjunto de atividades econômicas de produção, distribuição, consumo, poupança e crédito, organizados sob a forma de autogestão. Sendo importante ressaltar que ela representa elementos positivos.

Para Singer (2002), no mundo capitalista a desigualdade é crescente, há verdadeira divisão de opiniões entre ganhadores e perdedores. Sendo assim, as diferenças sociais devem ser consideradas como desigualdades e assim se tornam ganhadores e perdedores.

As diferenças entre pensamentos e conceitos, socialistas e capitalistas, resultam de forma diferente, pois as ações se divergem em apenas visualizar as vantagens e desvantagens dos sistemas, enquanto outros buscariam ações para combatê-los.

Analisando os conceitos de ambos os lados, tanto socialista quanto capitalista, podemos entender que na Economia Solidária mesmo com todo preceito de que sua causa está a favor de resultados coletivos, percebe-se que o que mais prevalece no final é o uso individual do capital gerado pelas ações da economia solidária. Sendo assim, isso comprova que as pessoas mesmo trabalhando em meios coletivos, se preocupam com a sua própria necessidade, agindo de tal forma que apenas prevalecem seus interesses, pois o que querem é sempre melhorar sua qualidade de vida.

\section{Potencialidades da Economia Solidária}

A Economia solidária chegou ao Brasil para combater o desemprego estrutural, visando à inclusão social das pessoas, apoiada na solidariedade e equidade, pois no modelo capitalista a desigualdade social é nítida e quanto mais o trabalhador possui mais ele quer, focando-se somente no lucro.

Segundo Pitaguari, Cordeiro e Lanza (2012), a Economia Solidária vem partir das condições socioeconômicas e políticas das últimas décadas, dos embates da sociedade civil diante da crise e do desemprego estrutural, surgindo como forma de aliviar as expressões geradas pela pobreza, pelo desemprego, ou seja, pela globalização. Sendo assim, tem como intuito aliviar a pobreza, proporcionar autonomia, focando somente no que é necessário para todos, além de ser uma alternativa à exclusão social e proporcionar uma nova forma de trabalho.

De acordo com Singer (2000), a Economia Solidária é a mais importante alternativa ao capitalismo, pois oferece uma solução pratica e factível à exclusão social. Mas, para que se torne realidade é preciso apoiar e promover às cooperativas de trabalhadores, para que elas possam absorver as pessoas que não tem lugar na economia capitalista. Assim sendo, ela vem para tirar à 
concorrência e dar lugar a cooperação, incluindo os que necessitam de trabalho e não conseguem mais.

Além disso, o trabalhador sente-se valorizado, pois dentro da Economia Solidária ele possui autonomia, pois ela é organizada através da autogestão, não possui chefe e participa de todas as decisões que são tomadas, lutando pela sua emancipação.

Portanto, a Economia Solidária é vista como uma nova oportunidade de geração de renda, para que as pessoas não se sintam excluídas no ambiente capitalista. Assim, as pessoas pobres que passam a fazer parte, tem a oportunidade de melhorar a sua condição de vida.

\section{Fragilidades da Economia Solidária}

Quando a economia capitalista está em alta percebe-se que há mais colocação no mercado de trabalho, assim a procura por atividades dentro da Economia Solidária diminui, pois as pessoas preferem se assegurar com as normas da CLT e contar periodicamente com uma quantia fixa como renda mensal.

Já a Economia Solidária visa somente o que é necessário, a igualdade e o coletivo, ela agrega as pessoas e não o capital, sendo assim, muitas vezes as pessoas que se inserem não são tão bem remuneradas.

De acordo com Singer (2001), no Brasil a crise do desemprego, manifesta-se por causa do desemprego "aberto", que inclui pessoas que procuram emprego e não exercem outra função, além dessa de procurar emprego. Mas, isso só ocorre em famílias que tem uma pessoa que possa arcar com as despesas, sendo assim, isso não ocorre com pessoas de famílias pobres, pois eles não podem ficar parados, se não encontrarem emprego em determinada área partem para outra, caso contrário, enfrentariam sérias dificuldades.

Sendo assim, o aumento do desemprego não é gerado por causa da falta de interesse de pessoas e sim porque não tem empregos em todas as áreas para todos, pois algumas pessoas são exigentes e só trabalham naquilo que elas querem, ou seja, escolhendo o emprego. Além disso, o mercado financeiro não está em um bom momento, isto é, os juros estão altos, juntamente com a inflação, com isso as empresas vão fechando e os empregos diminuindo cada vez mais. Assim, a proposta da Economia Solidária apresenta possibilidades para novos trabalhos e geração de renda, diminuindo desemprego. 


\section{CONCLUSÃO}

As pessoas necessitam perceber que, na cidade estão presentes todos os tipos de pessoas, mesmo com a divisão do centro com a periferia, existindo os ricos e pobres, chefes e subordinados. Só que elas se esquecem de que um precisa do outro, pois um proporciona o emprego e outro a mão de obra.

Com relação à proposta da Economia Solidária, acreditamos que ela tem a preocupação de solucionar problemas comuns a essas pessoas com poder aquisitivo reduzido, porém, também nos apresenta que nem sempre as ações estabelecidas na proposta irão apresentar soluções positivas de forma imediata.

Considerando a forma e a quantidade de trabalho que é apresentada para essas pessoas, declaram não ser suficientemente remunerados para tal. Assim, apresentam dificuldades com relação ao poder aquisitivo no momento que querem adquirir bens econômicos no mercado, pois se deparam em situações que não possuem esse direito de posse.

Portanto, levando em conta que a Economia Solidária é muito recente, sendo um novo conceito, com uma proposta de ações de melhoria. Vimos que isso, nos leva a acreditar em uma proposta que só será realmente positiva em longo prazo. Para que isso seja confirmado, é de extrema importância que as pessoas envolvidas em um projeto de cunho da Economia Solidária, tenham como princípio agir de forma otimista, apostando em seus próprios esforços, estabelecendo planejamentos principalmente na questão financeira, pois só assim verão seu poder aquisitivo e com isso sentir-se incluído socialmente.

\section{REFERÊNCIAS}

BARROS, J. Inclusão Social. 2015 Disponível em: <http://www.brasilescola.com/educacao/inclusao-social.htm>Acesso em: 07 jun.2015.

GODOY, T. M. P. A. Economia Solidária na cidade capitalista: Conflitos e contradições da reprodução do capital no espaço urbano. Unesp, Rio Claro, 30 maio, 2008 Disponível em: <http://www.ub.edu/geocrit/-xcol/181.htm>Acesso em: 01 jun.2015.

OLIVEIRA, P. A. Desemprego estrutural. Faculdade Marechal Rondon, São Paulo, jan. 2004. Disponível em <http://www.fmr.edu.br/publicacoes/pub 08.pdf> Acesso em: 29 jul. 2015.

PITANGUARI, S.O.; CORDEIRO, S.M.A.; LANZA, L.M.B. A Sustentabilidade da Economia Solidária: Contribuições multidisciplinares. Londrina: Universidade Estadual de Londrina, 2012.

SINGER, P. Economia Solidária: um modo de produção e distribuição. In: SINGER, P. SOUZA, A.R. A Economia Solidária no Brasil: A autogestão como resposta ao desemprego. São Paulo: Contexto, 2003. p. 11-30. 
WELLEN, H. A. R. Contribuição à crítica da 'economia solidária'. Universidade Federal do Rio de Janeiro, jan./jun. 2008. 